\title{
Manual Materials Handling
}

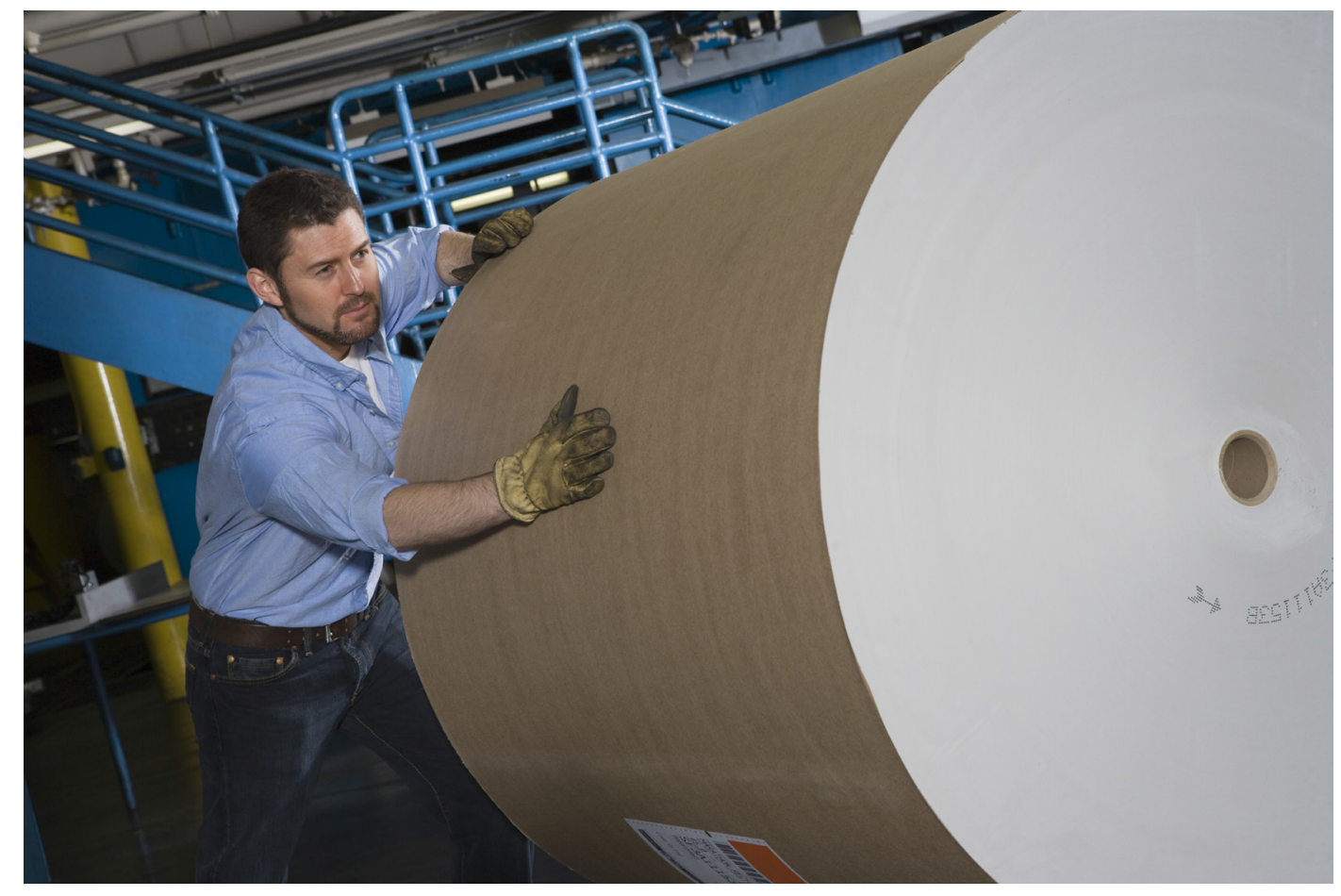

Image reproduced with permission from bikeriderlondon/Shutterstock.com. All rights reserved.

\section{THIS CHAPTER PROVIDES:}

- Descriptions of manual materials handling principles.

- Some examples of logistics solutions.

How to cite this book chapter:

Berlin, C and Adams C 2017 Production Ergonomics: Designing Work Systems to Support Optimal Human

Performance. Pp. 175-188. London: Ubiquity Press. DOI: https://doi.org/10.5334/bbe.j. License: CC-BY 4.0 


\section{WHY DO I NEED TO KNOW THIS AS AN ENGINEER?}

In most cases of manual assembly, the materials that become the actual product need to be transported to and from the workplace we are designing. While logistics and manual materials handling is a large, well-researched subject that deserves a book of its own, it is helpful for a production engineer to be aware of some basic principles of manual materials handling. This knowledge includes principles of packing, delivery, presentation in a particular order, and some modern industrial "tips and tricks" that are related to the knowledge you gained about cognitive aspects in Chapter 5.

Knowing about material flows is a good way to get ideas for presenting components to a worker - this may not only relieve them of unnecessary physical loading, but may also serve to improve understanding of how to assemble the product. At the same time, environmental or economical demands may sometimes dictate that a particular material flow should be used, and in such cases it is helpful for a production engineer to understand whether a) human concerns are the priority, and therefore the method of materials delivery should be changed, or b) if the other demands on the total production system may be of a higher priority, meaning that the workplace itself should be designed to work around the chosen materials handling principle.

\section{WHICH ROLES BENEFIT FROM THIS KNOWLEDGE?}

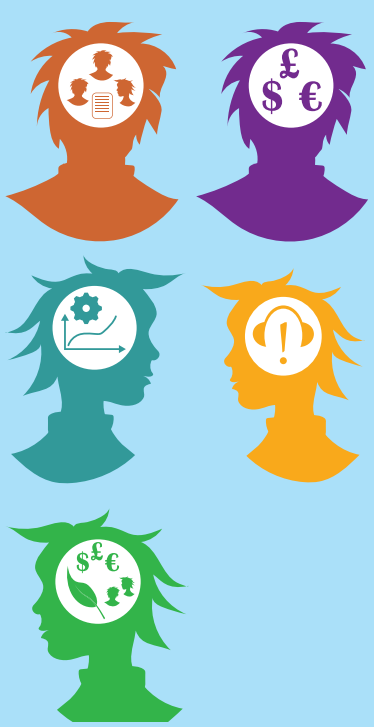

Materials Handling may traditionally be seen as the domain of logisticians and production planners - naturally, this means that it overlaps with many concerns of workplace design, in particular for assembly line settings. For this reason, many different roles may be interested in the economical aspect connected to the use of floor space and set-up time. The manager/ leader and the purchaser may have a basic understanding of certain materials principle and may regard this as just another investment but should know the relative pros and cons of choosing one over the other, as there is no single, superior method, and all of them bring benefits that come at different costs, from different system perspectives. The system performance improver and work environment/safety specialist need to know the impacts on performance, efficiency and worker safety for each materials feeding principle, so as to know how to reason about impacts and turn a proposal into a business case. The sustainability agent is likely to be concerned with issues of materials handling from an environmental perspective (material use and scrap avoidance), so having knowledge of the different $\mathrm{MMH}$ principles' social and economical impacts helps to integrate the knowledge into a sound sustainability assessment of how to supply material. 


\subsection{Function of manual materials handling}

Lean production is all about maximizing value through the optimization of flow and elimination of waste. One way to reduce waste is to decrease the amount of handling associated with materials and parts as they go through the production chain (Jonsson et al., 2004) - i.e. materials handling. Reducing the amount of handling not only improves efficiency and delivers cost savings, but also provides a more operator-friendly work environment, with fewer risks that could lead to MSDs. While there are many forms of handling equipment in existence, like conveyor belts, picking robots, trucks and trolleys, a large number of manual activities are still being performed in the production environment. When material is handled without the aid of automated devices, it is classed as manual materials handling (MMH).

Materials handling is defined as:

"The movement of raw materials, semi-finished goods, and finished articles through various stages of production and warehousing" (Compton, 1998).

While the logistics of transporting parts to and from the production site come under the broad umbrella of materials handling activities and need to be addressed by the planner, this book will not cover the logistics associated with supply and delivery. We will instead focus on materials handling from an internal factory perspective - that is, the nature of material flow within the factory, surrounding the assembly line and the tasks closely related to assembly activities. Material flow, container positioning, the supply of components to the right workstations when needed and the design of storage containers are all key characteristics of materials handling.

\subsection{Issues and risks arising from poorly designed MMH systems}

The design of workstations and assembly lines with regards to $\mathrm{MMH}$ has a direct impact on both the product's time-to-market and the health of the operator. The overall aim of the workstation is to ensure a high rate of productivity is achieved and customer demands are fulfilled without creating any unnecessary strain on the operator. Part of the responsibility for creating such workplaces falls on production engineers.

In this book we discuss the impact of loading on the body (Chapters 2 and 3) and the negative impact some work environments can have on the human body (Chapter 12), leading to the onset of MSDs. The materials handling sector is found to be a large contributor and responsible for causing many lower back related injuries, and hence absenteeism (see Chapter 11). In fact, the problems associated with materials handling are what led to the creation of the NIOSH analysis method that was introduced earlier in Chapter 8. Bending over to pick material out of pallets or picking up pallets or large heavy components is a common injury trigger (Neumann et al., 2006).

Internal factory MMH activities that are associated with assembly exist in the following forms:

- administration activities (e.g. auditing and reporting)

- taking necessary components out of storage containers

- putting components into packages 
- downsizing or re-packaging components

- kitting and sequencing of components

- delivering the components to specific assembly workstations on the production line

- assembling components to form sub-assemblies

- transporting sub-assemblies down the production line to the next workstation

- combining sub-assemblies to form larger sub-assemblies or the final product

- packaging of sub-assembly or product

- disposal and handling of packaging material

Each of these tasks can involve walking large distances, lifting, pushing, pulling or carrying heavy loads, and highly repetitive movements. Given the diverse nature of all these tasks, a number of different considerations should be taken into consideration in parallel when designing the workplace. Otherwise, there is a risk that optimization efforts will be targeted only at a micro level, but the overall system performance will end up being sub-optimal (Hanson, 2012). There is also a danger that system efficiency is considered more important ${ }^{1}$ than the operator's safety and well-being, leaving them with physically demanding tasks in obscure body positions. In line with the lean approach to production, walking to collect necessary components and handling them is considered non-value adding work, and therefore efficient materials handling aims to combat "unnecessary movement". So to reduce such "waste", production facilities strive towards workstation and assembly line layouts where the need for the operator to move away from their assembly station is eliminated, or at least minimized.

\subsection{Different types of $\mathrm{MMH}$}

Getting the right part in the right place, with the right orientation, at the right time is crucial to efficient production both in terms of time and cost. The characteristics of the products and individual components being manufactured can have a profound impact on the nature of how they are handled. Size, weight, shape, product variants, surface finish and demands of components are all product attributes that have an impact on materials handling (Hanson, 2012). Products with complex shapes involving hooks or springs are more likely to get tangled with other components, adding additional non-value adding actions to the work of the operator. Products on the same assembly line may also come in different variants. So while the core components remain the same, some subtle variations may mean that some parts will differ - and consequently, so will the assembly sequence. In some instances, this can involve workers sorting through numerous versions of the same basic component in search of the suitable one for the product variant in question. Ensuring that workers can pick the right parts for different product variants as quickly as possible - with the least number of touches and without overloading their body - is a responsibility for the workplace designer. Large or heavy components can be difficult to handle and move, which in some cases presents a higher level of injury risk for the worker. In comparison, fragile components with sensitive surfaces that can become easily damaged will require additional care (and possibly additional physical strain) during assembly activities.

One way to speed up the MMH process and ease the work of the operator is to take away the need for them to search and choose; if all the necessary components for that product variant are laid out before them in the right quantities, the need to choose the right component from the parts shelf is eliminated. Another key constraint in factories is that space to store material containers is at a premium, 
particularly near the assembly line. This has often caused companies to adapt their materials handling processes to target economic efficiency.

The following four materials feeding methods are the main conventional ways to supply material:

- Line stocking

- Batching

- Sequencing

- Kitting

Deciding which materials feeding system approach to adopt is a key concern for all production facilities, which directly impacts the nature of the assembly tasks conducted and the assembly lines' overall performance. Each method will be discussed in more detail below; however, the main emphasis will be on kitting.

\subsection{Line stocking}

Line stocking is one of the more traditional materials feeding methods. It is also referred to as bulk feeding, continuous replenishment or point-of-use storage systems (Limère et al., 2011). Generally these systems have some degree of automation, are fairly inflexible and are specialized to a certain product, only allowing for a low degree of product variation. In line stocking, full containers of each component type are delivered in bulk to the assembly line in the same containers that they were shipped in from the suppliers (Hanson \& Brolin, 2013). Each component type is stored in a different container, and all the containers are stored next to the assembly line.

Benefits of line stocking include:

- No need to pre-process or re-arrange parts.

- Stock is continually available at the assembly line (depending on the replenishment method).

- If a part is defective, it is very easy to select a new one from the container.

Disadvantages of line stocking include:

- Capital is tied up in stock.

- The shop floor becomes crowed with containers and pallets.

- Lack of space both at the production area and workstation, especially if many product variants are produced.

- A lot of time is spent walking, removing packaging, searching for and collecting the correct parts in the right quantities.

\subsection{Batching}

Batching is commonly used when products are made in response to a specific customer order. Typically this method is used when there is a mid to low volume of products required, with a limited variation in product type. The material is provided for a specified number of objects that are to be assembled. 


\subsection{Sequencing}

In the sequencing method, the number and type of parts needed for a specified number of objects to be assembled are displayed at the assembly station. For situations when only a small number of components are assembled per station, this method is recommended rather than kitting, as there is little value in taking time to make kits for each station when only a few components are necessary.

\subsection{Kitting}

Kitting is the term applied to the practice of collecting a predetermined amount of material in the form of components and/or sub-assemblies in containers and delivering them to the assembly line, to support one or more assembly operations for a given product or shop order (Bozer and McGinnis, 1992). The containers or bins storing the necessary material are known as kits. Kitting essentially splits the assembly process into two distinctive phases; the collection of the required material, followed by the part assembly. Kitting can be done in two forms: a travelling kit or a stationary kit (Bozer and McGinnis, 1992). A travelling kit is one that moves down the assembly line at the same time as the object being assembled, so each kit contains material for several different workstations. Stationary kits, on the other hand, only contain the necessary parts for one specific workstation.

Due to the nature of the product and factory layout, kitting is a necessity in some industries - however, it is important to note that kitting is not necessarily the superior choice and it is rarely implemented from the outset. In an ideal world, a product would have a relatively low number of components (based on Design For Assembly, DFA principles) and be designed in such a way that makes it simple to assemble; however, this is rarely the case in reality. So in some circumstances, kitting is necessary and can be used to solve the following issues, which will be elaborated in the following sections:

- Lack of space

- Quality

- Flexibility

- Materials handling

- Learning

\section{Lack of space}

A common problem with line stocking is the amount of space required to store the large material containers for each component type next to the assembly line (Finnsgard et al., 2011). Kitting removes the need to have material pallets and containers located right beside the assembly line by only providing operators with the amount of material required to assemble one product/sub-assembly at a time, thus freeing up space on the shop floor. In reality, this means space is taken up elsewhere in the factory upstream of the assembly line, as the material still needs to be stored and a space needs to be allocated for the making of kits in the first instance. So in a holistic perspective, kitting can actually take up more space, since the original material containers still exist along with the new kitting containers - however, the value of space is relative to its proximity to the line itself, so it can still make good economical sense to devote space to kitting elsewhere. This liberation of more space by the assembly line is often used as the number one business case when kitting is implemented in Swedish factories (Corakci, 2008). Internationally, kitting is most often used to enable mixed model assembly lines in automotive assembly. See also Flexibility. 


\section{Quality}

As previously mentioned in Chapter 5, kitting can also contribute to enhanced quality. Since the operator does not need to focus on what parts to assemble, they can instead focus all their energy and efforts on the assembly tasks (Bäckstrand, 2009; Medbo, 2003). Kits also provide a memory aid to operators by clearly showing if any components have been missed or forgotten during assembly, so issues can be corrected as soon as they occur. To ensure high quality and minimize confusion, kitting trays should have both component-shaped holes indicating where everything belongs and part identification numbers that correspond to the large bulk storage containers. Having inserts in kitting containers that prevent component movement can also protect sensitive surfaces from getting damaged (Corakci, 2008).

\section{Flexibility}

Kitting is considered to be a more flexible materials supply medium than line stocking (Sellers \& Nof, 1986; Bozer \& McGinnis, 1992). Providing material in kits rather than large storage containers facilitates the making of product variants at any workstation, since the issue of space limitation is removed. Kitting also encourages operators to be more flexible as it better equips them to assemble different product types when all components are presented in a logical manner.

\section{Materials handling}

In the case of kitting the total materials handling time can be seen as the sum of materials handling by the assembler, materials handling during kit preparation, and internal transportation to get the parts to the assembly line. The use of kitting is believed to save time as the need for the assembler to walk around, search through containers and collect material for each individual product is eliminated. Theoretically, these accumulated time savings can be transferred to justify the employment of a kitter (although other staffing management issues may limit this possibility).

Kitting also means there is less variation in the time to complete tasks, as handling and walking can significantly vary between workers dependent on individual strength, body size, etc. Most kit preparation stations involve some sort of picking support system, e.g. pick by light or voice, to ease the cognitive load on the operator and maximize productivity. Kitting is somewhat limited to small or medium sized components, since some larger components can't fit into a generic kitting container. Having said that, in some cases rack systems are used rather than containers for large components. In such instances a hybrid of line stocking and kitting is used. Typically, fasteners aren't included in kits as they are frequently used on many product variants, can easily be dropped and lost (which would be a problem if the assembler is supplied with an exact number of them), and don't require a large volume of space to store in bulk (Hanson \& Brolin, 2013). Alternatively, fasteners can be stored in small containers beside the power tools so operators can just grab a handful of them when collecting the tools.

\section{Learning}

As previously discussed in Chapter 5, kitting aids the operator by positioning the material in the container in such a way that it acts as a work instruction, showing the assembly order. Implementing 
standardized work associated with kitting also provides benefits from the assembler's perspective. The holistic learning strategy provided by kitting leads to shorter learning times overall during the introduction of new product variants, or for new employees (Medbo, 1999).

Additional benefits that kitting can bring:

- pace keeper (takt time)

- facilitated materials control (components are at hand)

- better visibility of the shop floor and assembly line flow

\section{Kitting summary}

While kitting provides a number of benefits when successfully implemented, it is also important to be aware of its weaknesses and the potential issues it can cause. The success of both kitting and continuous flow is very much dependent on the setting and exact way in which these processes are applied.

Often, containers are designed in such a way that the parts can only be positioned one way, making it easier for both the kitter and the assembler. However, in situations where there is a high degree of product variance, there will be a need for a number of different containers. The biggest problem is when the product design is changed, requiring a different sequence or components, in such a way that the containers become obsolete and have to be redesigned. In some cases kitting can lead to a higher number of man-hours, as the material has to be kitted, taken to the assembly line and then assembled (Sellers \& Nof, 1986; Bozer \& McGinnis, 1992). So it is only worthwhile to implement kitting if it is expected to provide numerous benefits in other areas that balance this out - such as higher quality, increased flexibility (product mix, new products, volume flexibility, changed takt time), higher production capacity, reduced time variation between assemblers, and the provision of more space on the shop floor.

If a component is missing from a kit, a replacement is sometimes "stolen" from another kit, which can lead to shortage issues in kits further down the line and increase the amount of handling. In situations where parts can't be taken from another kit, it may be necessary for the operator to walk all the way to the kitting area and retrieve the necessary component. This slows down the whole assembly process and in some cases can force stoppages. In contrast, such an issue wouldn't occur if continuous flow were used, as the distance from the storage container to the assembly line is significantly shorter (Hanson \& Brolin, 2013). Kit preparation also means that parts are handled an additional time, which in the case of fragile or sensitive parts increases the risk that they will become scratched, warped or damaged. Like the implementation of any new change in a production environment, kitting has costs associated with its introduction, as the setup of any new process will require layout modifications, new equipment and staff training. In instances where kitting is determined as the best option, managers should be wary of "over- kitting" and kitting unnecessary parts. Kitting is often used in parallel with line stocking, where high-variation products are kitted and all the other parts are line-stocked.

\subsection{Workstation design principles}

Given that materials handling affects both the physical workload of operators and the performance of the system, it is worth outlining some key guidelines and principles concerned with the design and layout of workstations. 
The following principles will be discussed in more detail below:

- Working height considerations

- Storage container considerations

\subsection{Working height considerations}

The back and the wrists are often at risk in materials handling tasks. With well thought-out designs and layouts such risks can be minimized, enhancing the work environment for the operator. Removing material from containers often involves bending or stretching and is identified as a high-risk activity, especially given the high degree of repetition associated with the collection of material and assembly activities.

The height and angle of the shelves storing the containers, and their location relative to the assembler, are a key design consideration. The frequency of tasks involving back bending and arm raising should be identified and designs put in place to reduce or eliminate these high injury-risk occurrences.

Kitting can somewhat lessen bending motions, as components are stored in the kitting container which is then positioned at a suitable height relative to the worker and the workstation. Some workstations are even large enough that kitting containers can be stored on the same surface where assembly operations are conducted - however, this is not always the case, and is very dependent on product and part size. In situations where there is limited space preventing the operator from accessing all the necessary material from their normal working position, a common guideline is that the most frequently used material should occupy the best position. Generally, taking a step to collect material is considered better for the body than staying in the same place and twisting or bending to access the components.

While the use of such containers and layouts have potential to eliminate undesirable body postures and high loads, the time saving could trigger a phenomenon dubbed the "ergonomics pitfall" (Westgaard \& Winkel, 1997), which means that time gains are used to spend even more time working (e.g. on assembly), which in turn could lead to an increased risk of repetitive strain injury. If this intensification of work occurs unintentionally, it may introduce its own new risk factors and problems, and the ergonomic benefit that was meant to increase safety and reduce risk is lost.

Given that operators have different body characteristics and work at numerous different stations, it can be beneficial to have containers stored on height-adjustable shelves, which the operator can set to an appropriate height at the start of their shift. However, this obviously increases equipment set-up cost and some time will be taken every time the height is adjusted, so a review would be necessary to check whether the gains from such a system (e.g. decreased operator strain and time savings) justify the setup.

Some companies have been known to develop their own storage design guidelines that strive to lessen the physical strain of materials handling - one example is Volvo's VASA model (Backman, 2008; Finnsgård et al., 2011), which is based on acceptability criteria values from Volvo's own corporate standard (Volvo, 2014); see Figure 10.1. By extension, its "translation" into material façade risk zones (by Finnsgård et al., 2011) is shown in Figure 10.2.

Components stored at heights that cause a high load on the body are given a red classification; typically, these are very high up or very low down. Whereas components that are easy to collect without causing any discomfort are given a green classification. Based on this model, container layouts are normally set so that the most frequently used are easiest to obtain. 
Work load, work postures, working movements

Assessment templates

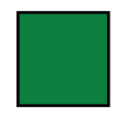

Non-injurious impact

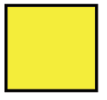

Possibly injurious impact depending on number of movements or the duration of the posture

Injurious impact when occurring for longer periods of time, lengthy or often

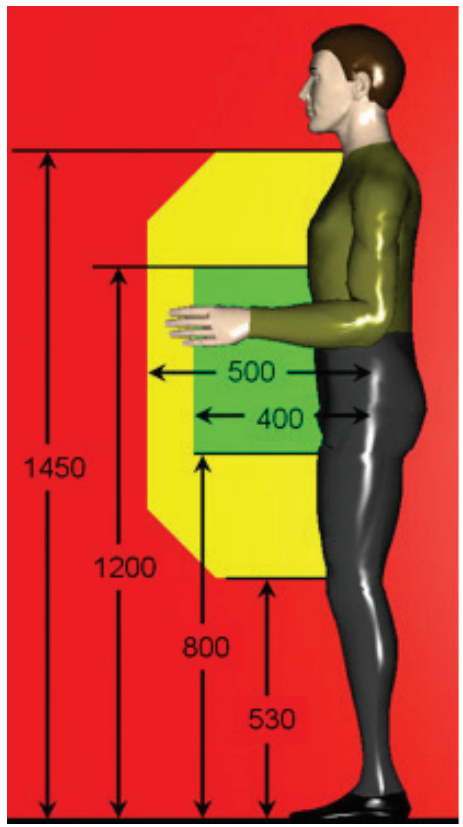

Figure 10.1: Criteria levels from Volvo's internal ergonomics standard (Volvo, 2014), commonly applied at numerous Volvo production facilities. Exposed material is classed into one of three categories (red, yellow or green) based on the lifting frequency impact on an "average" $172 \mathrm{~cm}$ tall person.

Image reproduced with permission from B. Johansson/Volvo. All rights reserved.
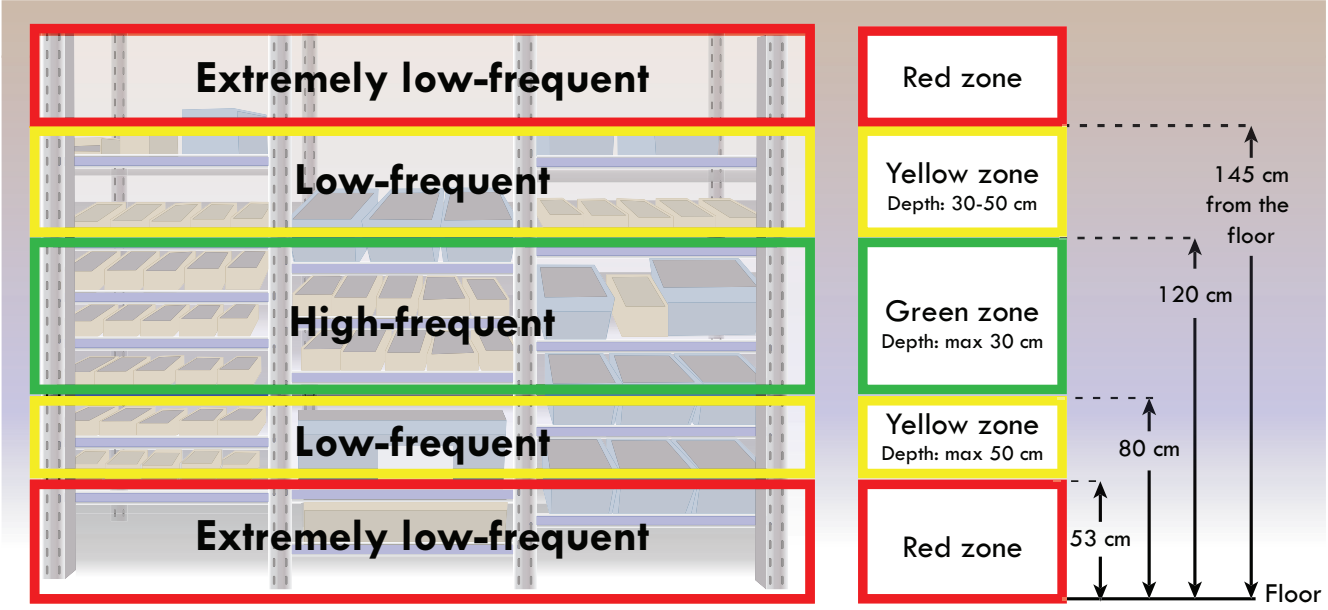

Figure 10.2: The VASA model translated into red, yellow and green zones for a material façade, indicating how frequently it is acceptable to handle materials at each height.

Image by C. Berlin, based on Finnsgård et al. (2011). 


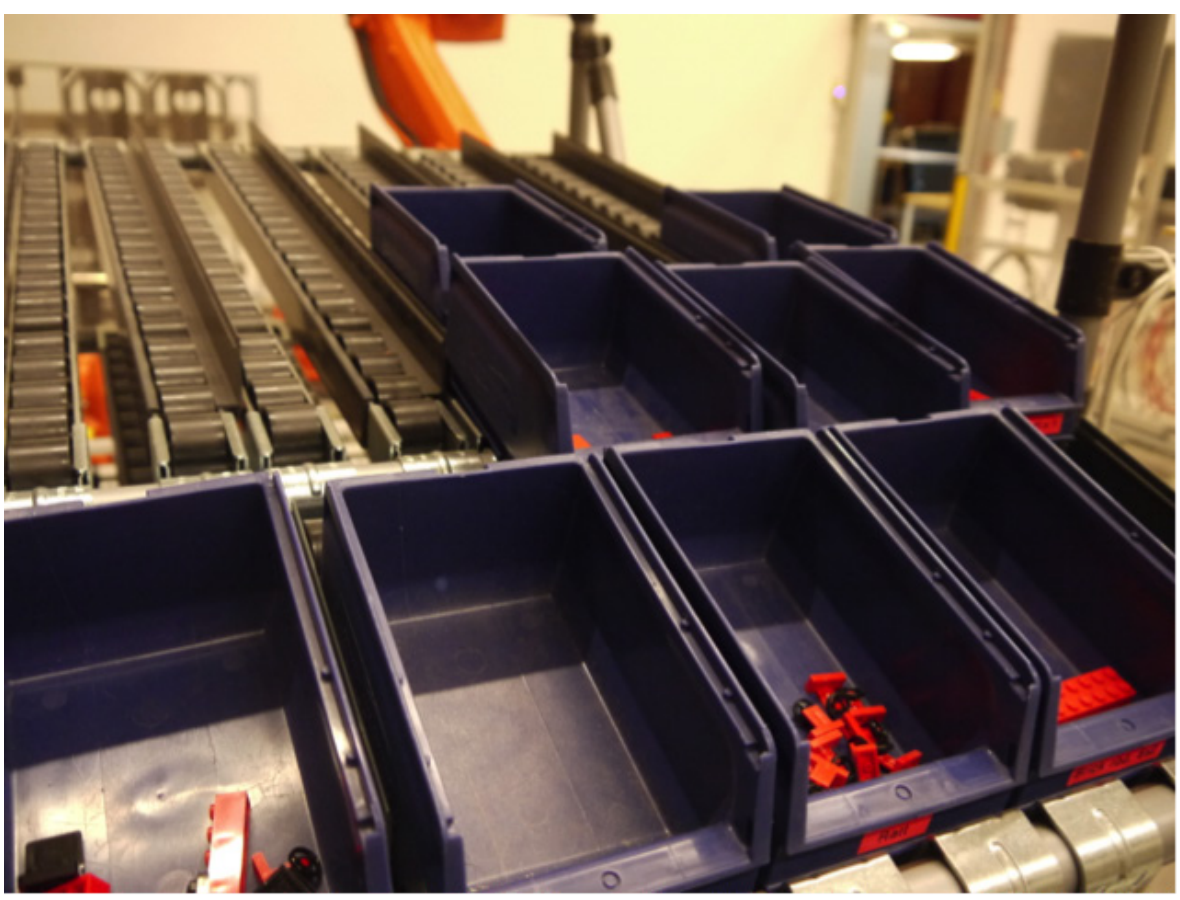

Figure 10.3: Gravity flow rack and kitting containers.

Photograph by C. Adams.

\subsection{Storage container considerations}

The sizing and positioning of storage containers also contributes both to the efficiency of materials flow and the injury risks for assemblers. Material containers are stored on a shelving rack, also known as a façade.

A study (Neumann \& Medbo, 2010) was conducted comparing the use of large containers (Euro pallet sized, $800 \mathrm{~mm} \times 1200 \mathrm{~mm}$ ) to narrower boxes. Through a biomechanical analysis studying the loads the human body is subjected to during work, it was identified that narrow boxes reduce both peak spinal loads and shoulder loads. The study also showed that the use of narrow boxes enabled shorter material supply racks to be used, providing more space next to the assembly line and decreasing the overall assembly time by reducing the amount of walking needed to collect parts. Smaller boxes also enable parts to be stored closer to each other, leading to less time being spent walking and collecting material - this is a key benefit for scenarios involving many product variants, with numerous material containers. The use of narrow boxes stored in racks on wheels ${ }^{2}$ provides a higher degree of flexibility, as the whole rack can simply be rolled to a new location if changes are made to the layout.

Another study (Finnsgård, 2013) has confirmed the benefits of smaller storage containers, reporting a 23\% reduction in materials handling time after a redesign was made utilizing smaller containers. The same study also identified a $67 \%$ reduction in space needed to expose the components, resulting in substantially more space next to the assembly line. Using open-fronted containers or angling 
them towards the operators also provides benefits, such as making it easier to see exactly what is in the container (reducing neck strain) as well as improving accessibility, reducing unnecessary wrist extension and flexion. Gravity flow racks are often used to hold storage containers and aid accessibility (Figure 10.3). These inclined shelves mean that when the front container is taken out, the next container will move forward to the front of the rack. They also enable kitters and assemblers to work simultaneously without getting in each other's way, as the kitter can stock the containers from the back while the assembler collects material from the front.

\section{Study questions}

\section{Warm-up:}

Q10.1) Name at least three risks for quality and safety that can stem from poor $M M H$ ergonomics.

Q10.2) What are the pros and cons of kitting?

Q10.3) What are the pros and cons of line stocking?

Q10.4) What are the pros and cons of using small containers?

\section{Look around you:}

Q10.5) What are some good solutions for MMH that you have seen in industrial or retail settings? Think of examples where stocks need replenishment fairly frequently.

Q10.6) Observe the physical arrangements of the goods in a warehouse store (i.e. a selfservice shop where customers fetch goods spread out over a large area), for example a home improvement store. Would you say that the store has provided kitting or sequencing solutions to enable customers to easily acquire all the materials and tools they need to assemble goods at another location, or do customers need to visit several different areas of the store to fetch all they need?

\section{Connect this knowledge to an improvement project}

- MMH may sometimes be regarded as a separate area of responsibility from workplace design, but taking it into consideration helps to ensure that materials presentation is appropriate for assemblers, and that the needs and limitations of materials handlers are included in design proposals.

- MMH principles like kitting, batching, etc. can be used as "solution kits" to address physical, cognitive and psychosocial aspects of ergonomics, since component visibility, time-keeping, quality control and teamwork may all be positively impacted by appropriately chosen $\mathrm{MMH}$ solutions. 


\section{Connection to other topics in this book:}

- Some ergonomics evaluation methods (Chapter 8) are specifically targeted towards $\mathrm{MMH}$ (see section 8.2.3), e.g. KIM and the Liberty Mutual manual materials handling tables.

- Many MMH principles are based on avoidance of excessive physical loading (Chapter 3) and sound cognitive ergonomics principles (Chapter 5).

- The economics of a workplace (Chapter 11) may be positively impacted by well-designed $\mathrm{MMH}$ - not only due to fewer injuries and increased speed and efficiency, but also because some $\mathrm{MMH}$ solutions can free up valuable floor space.

\section{Summary}

- Materials handling systems have a significant impact on the performance of assembly systems.

- Use a holistic view, weighing up all the trade-offs when selecting which materials handling method to use.

- Four main methods in operation: line stocking, sequencing, batching and kitting.

- Kitting provides benefits in the areas of quality, lack of space, learning, materials handling and flexibility.

- Workstations should be designed taking into consideration walking distances, positioning of components and storage containers relative to the assembler and the frequency of component selection.

\section{Notes}

${ }^{1}$ Of course, this misconception can be best avoided by adopting the design philosophy that well-being and system efficiency are mutually compatible, and that solutions can be found to benefit both.

${ }^{2}$ For safety reasons, these should of course be wheels that lock.

\subsection{References}

Bäckstrand, G. (2009). Information flow and product quality in human based assembly. PhD thesis, Loughborough University, UK.

Backman, K. (2008). VASA Ergonomic requirements - Volvo Corporate Standard STD 8003, 2.

Bozer, Y. A. \& McGinnis, L. F. (1992). Kitting versus line stocking: A conceptual framework and a descriptive model. International Journal of Production Economics, 28: 1-19.

Compton's Interactive Encyclopaedia. Cambridge, Mass: Softkey Multimedia, 1998.

Corakci, M. A. (2008). An evaluation of kitting systems in lean production. Master's thesis. University of Borås, Sweden. 
Finnsgård, C. (2013). Materials exposure: The interface between materials supply and assembly. PhD thesis, Chalmers University of Technology, Sweden.

Finnsgård, C., Wänström, C., Medbo, L. \& Neumann, P. (2011). Impact of materials exposure on assembly workstation performance. International Journal of Production Research, 49(24): $7253-$ 7274 .

Hanson R. (2012). In-plant materials supply: Supporting the choice between kitting and continuous supply. PhD thesis, Chalmers University of Technology, Sweden.

Hanson, R. \& Brolin, A. (2013). A comparison of kitting and continuous supply in in-plant materials supply. International Journal of Production Research, 51(4): 979-992

Jonsson, D., Engström, T., \& Medbo, L. (2004). Some considerations relating to the reintroduction of assembly lines in the Swedish automotive industry. International Journal of Operation \& Production Management, 24(8): 754-772.

Limère, V., Van Landeghem, H., \& Aghezzaf, E.-H. (2011). Kitting versus line stocking in the automotive assembly industry: the influence of part characteristics, In: Belgian Operations Research Society, 25th Annual conference. 147-148.

Medbo, L., 1999. Materials Supply and Product Descriptions for Assembly Systems. PhD thesis, Chalmers University of Technology, Sweden.

Medbo, L., (2003). Assembly work execution and materials kit functionality in parallel flow assembly systems. International Journal of Industrial Ergonomics, 31(4): 263-281.

Neumann, W. P., Winkel, J., Medbo, L., Mathiassen, S. E. \& Magneberg, R. (2006). Production system design elements influencing productivity and ergonomics - A case study of parallel and serial flow strategies. International Journal of Operations \& Production Management, 26(8): 904-923.

Neumann, W. P. \& Medbo, L. (2010) Ergonomic and technical aspects in the redesign of material supply systems: Big boxes vs. narrow bins. International Journal of Industrial Ergonomics, 40(5): 541-548.

Shtub, A. \& Dar-El, E. M. (1989). A methodology for the selection of assembly systems. International Journal of Production Research, 27(1): 175-186.

Sellers, C. J. \& Nof, S. Y. (2007). Part Kitting in Robotic Facilities In: Robotics and Material Flow. Amsterdam: Elsevier Science Publishers B. V. pp. 163-174.

Volvo (2014). Ergonomic requirements - Application. Volvo Corporate Standard STD 8003, 29. [Online]. Available from: http://www.volvogroup.com/en-en/suppliers/useful-links-and-documents/ corporate-standards/search-for-standards.html [Accessed 12 Dec 2016].

Westgaard, R. H. \& Winkel J. (1997). Ergonomic intervention research for improved musculoskeletal health: a critical review. International Journal of Industrial Ergonomics, 20(6): 463-500. 